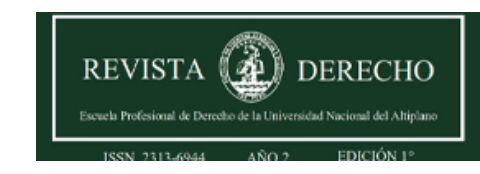

Revista de Derecho

ISSN: 2313-6944

ISSN: 2707-9651

revistaderecho@unap.edu.pe

Universidad Nacional del Altiplano

Perú

\title{
TRAICIÓN A LA PATRIA, LAS INCONDUCTAS DE LOS PERUANOS EN TIEMPOS DE CORONAVIRUS
}

Montes De Oca Vallenas, Noe Alexander

TRAICIÓN A LA PATRIA, LAS INCONDUCTAS DE LOS PERUANOS EN TIEMPOS DE CORONAVIRUS

Revista de Derecho, vol. 5, núm. 2, 2020

Universidad Nacional del Altiplano, Perú

Disponible en: https://www.redalyc.org/articulo.oa?id=671870937002

DOl: https://doi.org/10.47712/rd.2020.v5i2.84

\section{(c) ()}

Esta obra está bajo una Licencia Creative Commons Atribución 4.0 Internacional. 


\title{
TRAICION A LA PATRIA, LAS INCONDUCTAS DE LOS PERUANOS EN TIEMPOS DE CORONAVIRUS
}

\section{Betrayal to the country, the misconduct of peruvians in times of coronavirus}

Noe Alexander Montes De Oca Vallenas

Estudio Juridico "Montes de Oca Vallenas", Perú

alx_18943@hotmail.com

iD https://orcid.org/0000-0002-1496-0155
DOI: https://doi.org/10.47712/rd.2020.v5i2.84

Redalyc: https://www.redalyc.org/articulo.oa? $\mathrm{id}=671870937002$

Recepción: 30 Septiembre 2020

Aprobación: 25 Octubre 2020

Publicación: 27 Octubre 2020

\section{RESUMEN:}

La inesperada aparición de una mortal enfermedad de rápida proliferación entre las personas en el mundo, que ha cambiado nuestros hábitos de vida, sobre todo relucir ese actuar inhumano frente a nuestros compatriotas, por esta razón, se ha considerado que las conductas corruptas deban ser incorporadas al tipo penal del delito de traición a la patria, por la incorrecta actuación y la cruel indiferencia que existe a consecuencia del COVID-19, el aprovechamiento, la indiferencia, el egoísmo y que no importe la necesidad vital de los demás, perjudicando vilmente a los que más lo necesitan en momentos de crisis, evidencia que los hombres somos presas de la corrupción, que no descansa, se suman las miles de muertes en el país, producto de la existencia de esas conductas por gran parte de la ciudadanía a comportamientos tan insensibles hacen que parezcan innatos en los peruanos.

Palabras Clave: Comportamiento innato, delitos de corrupción de funcionarios, egoísmo, Emergencia Sanitaria por COVID-19, indiferencia, traición a la patria.

\begin{abstract}
:
The unexpected appearance of a deadly disease of rapid proliferation among people in the world, which has changed our habits of life, especially highlighting that inhuman act in front of our compatriots, for this reason, it has been considered that corrupt behaviors should be incorporated to the criminal type of the crime of treason, due to the incorrect action and cruel indifference that exists as a result of COVID-19, the use, indifference, selfishness and that the vital need of others does not matter, viciously damaging to those who need it most in times of crisis, evidence that men are prey to corruption, which does not rest, there are thousands of deaths in the country, as a result of the existence of these behaviors by a large part of the citizenship to behaviors so insensitive make them seem innate in Peruvians.
\end{abstract}

KEYWORDS: Innate behavior, crimes of corruption of officials, selfishness, Health Emergency due to COVID-19, indifference, treason.

\section{PRESENTACIÓN}

\section{El actuar del peruano pre y post pandemia.}

Hablar del comportamiento de los peruanos, es toda una gran mezcla de sentimientos, vasta apreciar la algarabía y alegría que provocan los triunfos de nuestro país en el exterior, lo cual evidentemente nos llena de orgullo e hincha nuestro pecho, como la clasificación de la selección al mundial, nuestros atractivos turísticos y porque no dudar de la exquisita gastronomía envidiada en todo el planeta, sin embargo, también encontramos comportamientos y sentimientos negativos, como la corrupción, la inseguridad y otros grandes problemas que tenemos como sociedad, uno de ellos es la falta de solidaridad que existe con los compatriotas.

NotAS DE AUTOR 
$\mathrm{Al}$ respecto, Cobo (2003) señala que cada uno de nosotros tenemos actitudes hacia casi todas las cosas o personas del mundo en las que hayamos pensado en algún momento, las actitudes son las formas de reaccionar (conductas, comportamientos) a algún estímulo producido por un ser vivo o por alguna otra cosa; cuando la respuesta la hacemos verbalmente se denomina opinión.

Siguiendo esa línea, estas conductas nada humanas que tiene el peruano siempre existieron durante todos los tiempos, es común y frecuente, resalta la falta de solidaridad entre nosotros, es tan natural frente a los problemas y la necesidad de los que menos tienen, parece tan normal hacerlo que hasta se podría decir que es innato, el aprovecharse del dinero de todos para beneficios propios, ver con total indiferencia las miles de muertes a consecuencia del COVID-19 y otras tantas conductas, son signos característicos que los peruanos somos altamente indolentes.

Establece Monroy (1994), las actitudes corresponden a las expresiones psíquicas del ser humano, que frecuentemente se encuentran en contradicción: se piensa que es malo fumar pero se actúa fumando, siente repulsión hacia el superior pero lo halaga, al ser las actitudes conductas, pueden ser desarrolladas o modificadas.

Esta contradicción la observamos en la actualidad, por ejemplo cuando le exigimos al gobierno que invierta en salud para protegernos del temible virus, empero, actuamos incumpliendo todas las normas de salubridad, saliendo a las calles por el simple placer de creer que este virus no es mortal, lamentablemente contagiamos a nuestros familiares, quienes fallecieron por nuestra imprudencia y después de esto no nos arrepentimos, tan solo buscamos culpables, sin aceptar nuestra responsabilidad, como nación se espera que todo esto acabe, que sea parte del aprendizaje que tenemos como seres humanos por nuestro bien.

\section{El SÍNDROME PSICOLÓGICO QUE AQUEJA A TODOS LOS PERUANOS}

Esta apatía, que podría enmarcarse dentro de la falta de solidaridad o de beneficencia frente a los demás, no solo es producto de los tiempos sino de las personas, la psicología social ha cualificado este fenómeno emocional, bajo el nombre del efecto espectador, conocido con el epónimo de síndrome de Genovese, este es innato en la gran mayoría de los peruanos, por la forma en la que actuamos ante la situación de que alguien se encuentre en estado de peligro y como es evidente no hacemos nada.

Manifiesta Fernández (2018), que muchas veces, en una situación de emergencia los observadores asumen que siempre será otro el que intervendrá, al punto de que todos terminan absteniéndose de hacerlo. Frente a esto, se manifiesta que al haber más personas alrededor, el cerebro razona bajo la premisa de que alguien ayudará, y si se observa gran cantidad de personas, se percibe una sensación de tranquilidad, con la convicción de que no todos se quedarán quietos, por lo que el compromiso de socorrer puede llegar a no existir en un observador.

Cuando una persona es víctima de cualquier delito, por ejemplo, un robo, solo atinamos a observar y en realidad no hacemos nada, es tan natural esta actitud y como manifiestan los expertos estamos ante un serio problema psicológico, peor aún en estos momentos, en lo que miles de ciudadanos sufren diversas carencias por causa de la pandemia, la corrupción y la indolencia provocan que los peruanos seamos inhumanos, efectivamente, no debe generalizarse porque no todos lo son, pero si la gran mayoría se aprovecha esta situación para solo obtener ganancias económicas a costa de los demás.

En últimas, nadie se responsabiliza o en caso de hacerlo, el compromiso se diluye de manera sustancial y se transforma, pero también puede ocurrir, que las personas pueden experimentar temor a ser evaluadas porque al prestar ayuda, el resto de espectadores pueden juzgar la forma como lo hacen, por lo que se prefiere no quedar expuestos Fernández (2018).

Los ciudadanos se resisten a verse involucrados en hechos de esta naturaleza, por lo que prefieren mantenerse al margen o dar la espalda, lo cual es muy común, estas actitudes deben cambiar, sin embargo, se 
aprecia personas que ayudan en recolectar alimentos o medicinas, hacen donaciones desinteresadas, esos son los guerreros que el Perú de todos necesita.

\section{Los típicos problemas en el comportamiento peruano.}

El peruano siempre busca y encuentra la oportunidad para transgredir las normas, el irrespeto y la indisciplina son los problemas de comportamiento tan natural, el bajo nivel de conciencia moral que existe en los peruanos que retan a la autoridad, que no creen en nadie, ni en el virus disfrutan romper las normas, no es una tendencia genética, es un problema del desarrollo, que ha sido reforzado durante la niñez y la adolescencia, son problemas cerebrales que provocan que los peruanos actúen de esa forma resaltando a la sociedad consumista y hedonista, como refiere Yamamoto (2020).

Como afirma el psicólogo, los peruanos tenemos un serio problema en nuestro actuar, lo cual es completamente cierto, siempre buscamos la manera de cómo sacarle la vuelta a la ley y para colmo siempre lo logramos, la indisciplina es común y durante la pandemia ni que decirlo es atroz, algunos ciudadanos siempre buscan aprovecharse de las normas para obtener ese placer, siempre buscamos pasar por encima de los demás, como aprovecharnos del dinero del Estado, subir a los vehículos cuando están llenos sin protegernos adecuadamente, incrementar los precios en artículos necesarios e imprescindibles y otras tantas actividades, pero siempre el peruano busca aprovecharse de la situación.

Si los peruanos nos comportaríamos como los ciudadanos de Europa y Norte América, seriamos una nación potencia con altos índices de civismo, se ha señalado por algunos estudiosos que este actuar es genético y no pueden dejar de tener razón, la educación dice mucho de un país y sobre todo de sus ciudadanos, el desarrollo es parte angular de nuestro comportamiento, a ello se suma la desobediencia, porque siempre buscamos hacer lo que se nos da la gana, además, no olvidar que siempre buscamos una justificación a todo.

La falta de valores y esa necesidad de consumismo, pretendiendo demostrar que quien más tiene es una mejor persona, lo cual no es cierto, en los países desarrollados las personas actúan para cuidarse a ellos y a sus familias, tampoco debemos olvidar, que se detienen a grupos de personas bebiendo como si la vida se les fuese a acabar, pues si siguen así el COVID-19 lo hará y no olvidemos que también a sus familias.

\section{La corrupción y su consideración como traición a la patria.}

La corrupción, es sin duda, un fenómeno social proliferante, frente a ello, se señala que somos un país corrompido de arriba abajo, de izquierda a derecha, transversalmente y longitudinalmente (Hildebrant, 2017), efectivamente, esto ocurre así y nadie piensa ni quiere hacer nada al respecto, lamentablemente permitimos que este mal continúe apropiándose de nuestras instituciones y ciudadanos causando graves secuelas.

Acostumbrados a ello, expresamos cotidianamente esa famosa frase, roba, pero hace, la cual deberíamos patentar, surgen las preguntas ¿De qué tribu primitiva puede haber salido una frase así? y ¿De qué nación vergonzante puede haber nacido una resignación de esa naturaleza, roba, pero hace? (2017), al responderlas sentimos vergüenza, claro si aún la tenemos, primordialmente si queremos progresar y avanzar como país, debemos desterrar de nuestro pensamiento esta peculiar frase, es lamentable no deseamos cambiar dicha realidad.

No debemos olvidar que la corrupción durante la pandemia no ha descansado en ningún momento, todo lo contrario, desde el inicio del Estado de Emergencia Nacional, la incidencia de la comisión de estos delitos se ha incrementado de forma exponencial, la Contraloría y la Fiscalía identificaron sobrevaloración de precios en bienes y servicios, simulación de procesos de compra, el re direccionamiento a proveedores y otras conductas ilícitas que no han cesado, los funcionarios y servidores aprovechan de forma muy descarada en aprovecharse de los recursos del Estado, obteniendo ganancias ilícitas, sin duda alguna, el grave daño que se le hace al país por esto es incalculable e inhumano.

\section{Cadena perpetua: ¿Son medidas efectivas para su represión?.}

La implementación de medidas correctivas son de urgencia nacional, una de las vastas propuestas es considerar a los delitos de corrupción dentro de los parámetros del delito de traición a la patria, como la forma 
más cruel que tendrá el Estado para reprimir este tipo de conductas lesivas y enquistadas en nuestro país, al respecto, el congresista Barrionuevo (2020) explica que su iniciativa legislativa busca endurecer las penas, sobre la justificación para tipificar los delitos de funcionarios como "traición a la patria” en situaciones de emergencia, porque estamos en una guerra, por eso se catalogara así, por los supuestos que afectan la seguridad nacional. La medida no es inconstitucional, al considerarlo traición a la patria, será drástico, además, el proyecto tiene la característica que se aplica en tiempos de paz y se penaliza los actos que afectan la defensa nacional.

Calificar como traición a la patria a todos los actos de corrupción, en este tipo penal muy grave, es sin duda alguna, un tema muy controvertido, por los distintos aspectos y posiciones al respecto, la gran indiferencia y la falta de solidaridad que existe frente a nuestros compatriotas es la justificación perfecta porque busca tutelar los intereses del país y de las personas para poder subsistir en tiempos de pandemia, por tanto, es el mecanismo jurídico que busca frenar los altos índice de corrupción, al mismo tiempo que los ciudadanos seamos más consientes sobre los problemas de los demás.

$\mathrm{Al}$ respecto Padilla (2020), sostiene que las propuestas no tienen proporcionalidad demostrando que en nuestro país no tomamos las cosas con seriedad, por ser un tema populista, de aprobarse, se cuestiona ¿inmediatamente al día siguiente no habrá corruptos?. Sobre la iniciativa que plantea la figura de traición a la patria - que en el artículo $140^{\circ}$ la Constitución, amerita la pena capital en caso de guerra, y el de terrorismo, conforme a las leyes y a los tratados de los que el Perú es parte obligada-, la pertinencia en una coyuntura como la actual, por más que lo quiera colocar como tal, suena rimbombante; pero no es traición a la patria.

Estas conductas, altamente lesivas para el país, deben ser reprimidas y castigadas de forma ejemplar, el aprovecharse de modo descarado de recursos del Estado debe ser considerado traición a la patria, estas conductas a simple vista se consideran inhumanas, lo cual es muy grave, que no solo se da por los funcionarios y autoridades, sino, por gran parte de los peruanos de a pie, que desde décadas pasadas se vienen aprovechando vilmente de los que más lo necesitan, se busca crear un cambio de actitud y de conciencia en la ciudadanía.

En ese contexto, López (2020) señala ¿qué cosa es traición a la patria?, la Corte Interamericana indico que no podemos aumentar el estándar de pena de muerte, adelantándose a la posibilidad de que se plantee la pena capital para los que incurran en este nuevo delito, es desproporcional. Entendiendo el espíritu, de que sea en una circunstancia de emergencia; pero, en todo caso, habría que hacerle una técnica más fina, porque, de lo contrario, termina siendo más grave que cualquier homicidio, se pondera la iniciativa como una suerte de intento de publicidad de la actividad política, porque en efectos prácticos, ya las penas son bastante graves.

Desde un enfoque multidisciplinario, se explica que el actuar indolente e indiferente es altamente peligroso, por su finalidad esencial, beneficiarse afectando la necesidad de otros, estas conductas afectan la gobernabilidad del país, la legitimidad de las instituciones, los derechos fundamentales de las personas, distorsionar el sistema económico y promover la desintegración social, aspectos muy importantes en un Estado solo se busca proteger a las personas y castigar toda conducta que afecte los principios por los que se rige.

\section{El retorno de la pena de muerte a los peruanos indolentes.}

La tan cuestionada pena de muerte, ha vuelto a ser utilizada por un sector de la política peruana para poder castigar a los sujetos que se aprovechan de la situación, ante ello la duda siempre persiste si un delito de corrupción deba ser considerado a la pena de muerte, existiendo delitos más graves, pero cuando esto es normal en los peruanos podría considerarse como adecuada para frenar la comisión de estos delitos.

$\mathrm{Al}$ respecto López (2020) indica que si hablamos de traición de la patria es porque se quiere emular lo que en su momento se hizo con la Constitución de 1993. Pero la Corte Interamericana ya dijo que en el caso peruano, no podemos aumentar el estándar de pena de muerte, adelantándose a la posibilidad de que se plantee la pena capital para los que incurran en este nuevo delito planteada por algún congresista.

La Corte es firme y clara al respecto, no debe existir en la legislación nacional la pena de muerte a los autores de este delito, pero que ocurre si esto se hace tan habitual que debe buscarse todos los medios necesarios para 
frenar de manera abrupta, porque como se sabe la corrupción es antigua más que el propio Estado, y peor en nuestro país cuando en plena pandemia los ciudadanos se aprovechan de los que menos tienen, lo cual no es evidentemente justo por las miles de muertes que día a día escuchamos por las noticias.

Es un tema muy controvertido, la pena de muerte a todo acto de corrupción en épocas de crisis, el tema tiene mucha cola por el momento, pero consideramos que lo que se busca en crear peruanos más conscientes que sean sujetos solidarios y con valores.

Creación de la conciencia y la unidad nacional.

Sobre este tema, Portocarrero (2015), añora la unidad nacional desde el liberalismo político, por ello afirma que la función civilizatoria del nacionalismo es crear una comunidad de personas que se sientan iguales, que sean capaces de obrar solidariamente, pues se reconocen como parte de una misma historia; caminando, además, hacia el mismo futuro.

Como nación debemos lograr la igualdad de todos los peruanos, sin discriminación, eso ayudara a crear la unidad nacional que tanto anhelamos. Si la libertad, la igualdad y la fraternidad lograran enraizar, entonces podemos hablar de una nación. Una sociedad donde prima la ley sobre el privilegio y donde existe la obligación, y la disponibilidad, para ayudar al que más lo necesita. Sobre todo resaltar el extremo de ayudar, nos hará crecer como personas y sobre todo otorga la satisfacción de haber hecho algo bueno en beneficio de una familia, que lamentablemente no tiene un techo donde reposar o hasta un plato de comida.

Las conductas que los ciudadanos tienen en distintos aspectos de su vida, ser ciudadanos de bien y con valores sería lo ideal, sin embargo, en el Perú se observa que la corrupción y la indolencia relucen notablemente, afectando nuestra identidad como país y como seres humanos, son esos hábitos de comportamiento muy cotidianos, que recrudecen actualmente en mayor magnitud por la crisis de este virus, afectando a todos pero más a las personas que menos recursos poseen.

Considerando que todo acto de corrupción deba enmarcarse dentro de los parámetros del delito de traición a la patria, por todos los aspectos indicados, permitirá que los funcionarios analicen bien si desean cometer estos delitos por su gravedad ante situaciones como la que vivimos y para los ciudadanos que cambien esa actitud tan inhumana que existe frente a nuestros compatriotas, sobre todo, si somos un país rico, en diversidad cultural, étnica, social, como es mencionado siempre somos un país de todas las sangres y lo único que tenemos que hacer para progresar es unirnos para crear la tan ansiada unidad nacional, creando conciencia en la unidad nacional, donde todos sin distinción alguna podríamos convivir.

Lo principal que debe buscarse en estos momentos es proteger a los ciudadanos, considerar como traición a la patria es la medida más adecuada cuando alguien le sube el precio a las mascarillas, a los balones de oxígeno que tanta falta le hace a miles de peruanos que mueren esperando interminables colas, el deber de todos los Estados es proteger los derechos humanos, la vida y la dignidad de las personas que más lo necesitan.

Por estas consideraciones, debe reprimirse con la más alta pena a quienes se aprovechan como pretexto de la pandemia, la injusticia que se vive en el país por el abandono a poblaciones vulnerables en verdad indigna, podemos observar esa cruel indolencia en los distintos rincones de la nación, la corrupción hace tanto daño, los miles de millones de soles, que bien pueden ser invertidos en medicinas, equipos médicos, alimentación y otros, la cual solo queda en bolsillos de pocos, muchos hablan de las dos pandemias que atacan cruelmente a nuestro país, resquebrajando esa alegría de personas, la indolencia de las autoridades y los ciudadanos que no son solidarios, somos altamente miserables.

\section{CONCLUSIONES}

La corrupción y la indiferencia le causan al país miles de pérdidas económicas y humanas, en estos tiempos de pandemia, los peruanos tenemos el firme deber de cambiar esta actitud que nos aleja de todo sentido de humanidad. 
La pandemia ha permitido que abramos los ojos, nos dio la oportunidad de mejorar estas formas de comportarnos frente a los demás, olvidémonos de colores de piel, idiomas, basta de ello, aprovechemos la oportunidad de crear la conciencia y la unidad nacional para el progreso del país.

Considerar todo acto de corrupción como traición a la patria es la medida legal que reprimirá a todos los que piensan que aprovecharse del dinero de todos, es correcto, lo cual no es así todo el daño que han ocasionado debe ser castigado de por vida, por estas consideraciones, debe impulsarse proyectos de ley que refuercen esta medida.

\section{REFERENCIAS BIBLIOGRÁFICAS.}

Barrionuevo, B. (28 de Abril de 2020). Proyecto de Ley No 5041/2020-CR: establece modalidades especiales al delito de traición a la patria en periodos de emergencia sanitaria. Proyecto de Ley. Lima, Lima, Perú: Congreso de la República.

Cobo. (2003). El comportamiento humano. Cuadernos de Administración.

Fernández. (2018). ¿Usted no ayuda a alguien en peligro? Sería por sindrome de indolencia? Psicología y mente.

Hildebrant, C. (01 de Febrero de 2017). Somos un país corrompido de arriba abajo y de izquierda a derecha. (R. Ideele, Entrevistador)

Lopéz, L. (23 de Abril de 2020). Traición a la patria y cadena perpetua: las propuestas de Somos Perú para castigar a funcionarios corruptos. (L. República, Entrevistador)

Monroy. (1994). La estructura del ser humano como fundamento de la educación en lo superior y para lo superior.

Padilla, V. (23 de Abril de 2020). Traición a la patria y Cadena perpetua: las propuestas de Somos Perú para castigar a funcionarios corruptos. (L. República, Entrevistador)

Portocarrero, G. (2015). La urgencia por decir" nosotros": los intelectuales y la idea de nación en el Perú republicano. Lima: GP Maish.

Yamamoto, J. (Agosto de 2020). Mayoría de los peruanos tiene un serio problema de comportamiento. (A. d. Andina, Entrevistador) 